\title{
Multiple Perspectives of Flexible Systems Management
}

\author{
Sushil
}

Published online: 17 May 2012

(C) Global Institute of Flexible Systems Management 2012

Flexible Systems Management is an emerging paradigm that relates with management of organizations placed in a chaotic business environment. The business environment has been changing over a period of time, which at times may be fairly turbulent and dramatic. This creates uncertainties and dynamics of high order. In order to cope with it, both for survival and growth in a competitive manner, business organizations have to look for innovative strategies and mechanisms. The paradigm of 'flexible systems management' (the focus of this Journal) is associated with multiple perspectives such as holistic management of organizational paradoxes with systemic flexibility; business agility infused by new information and communication technologies; innovation, strategic change and risk; and flexibility in various operations for achieving business excellence.

Managing systemic flexibility is closely related to managing paradoxes. A flexible organization is bimodal or ambidextrous in its design, which is able to carry two opposite things together. Some examples of managing ambidexterity through flexibility are centralization and decentralization, exploitation of strengths and exploration of new opportunities, and confluence of continuity and change. Flexibility in management may be both reactive to environmental changes and proactive to create new changes in terms of offerings, work practices, attitude, and so on. It is multidimensional in character and may carry different connotations in different contexts. Some prominent ones in vogue are: adaptability, responsiveness, openness, customization, localization, agility and many more. These

Sushil $(\bowtie)$

Department of Management Studies, Indian Institute of

Technology Delhi, New Delhi, India

e-mail: profsushil@gmail.com connotations encompass concerns of both variety and speed in multiple possible combinations.

Another dimension that is gaining momentum deals with business agility. Today's business is becoming highly volatile and virtual, as it has to be delivered through globally operated and highly integrated systems. Developments in information and communication technologies have provided IT agility that ultimately contributes to business agility. Cloud computing, social networking, knowledge based systems, search technologies, mobile transactions and many other developments have facilitated to carry out business in an agile manner to fulfill the requirements of continuously evolving landscape of business.

Another dominant perspective of flexible systems management is related with innovation and strategic change. In order to cope with business uncertainty and associated risk, a lot of innovation can be witnessed in modern organizations at the level of products/services, processes, management practices, and strategies. These innovations can be both proactive and reactive in nature and are intended to result in strategic renewal and transformation of a variety of organizations. From a flexible systems management perspective, strategic change that is leveraged with continuity is gaining relevance to manage impending risks of various kinds. Continuity, stability and identity have always been the subject matter of interest in strategy and organizations, but managing them in confluence with change and dynamism is of comparatively recent interest. This aspect of managing confluence of continuity and change is quite challenging and is an upcoming application of strategic flexibility.

While strategic flexibility is gaining significance, flexibility in various operations such as manufacturing, supply chain, finance, marketing, and human resource practices 
among others has been of interest for quite some time. In this context, developments in flexible and agile manufacturing systems have been well established in practice, globally. Flexible supply chains have also gained momentum in recent past. Flexible work practices at operational level such as flexi-time and flexi-place are in vogue in global corporations. These practices have received a fillip with developments in web based, video conferencing and related technologies resulting into evolution of virtual corporations. However, roadmaps for flexibility in financial, marketing and other business operations are yet to be sketched in the larger models of business excellence. Well established business excellence models such as Malcolm Baldrige and European quality awards still lack in integrating flexibility constructs in their design and implementation.

The gamut of flexible systems management is, thus, wide open and many more perspectives of the same are emerging on the scene. This Journal is intending to address a spectrum of flexible system management perspectives and, in turn, enable the evolution and enrichment of this paradigm of post-modern management. It aims to bring out a healthy blend of traditional as well as modern management thinking to meet the challenges of emerging business reality in a technologically and knowledge intensive world order. This kind of complex and chaotic landscape would require new thought processes and innovative business practices. These together would crystallize as a futuristic paradigm of management, and this Journal would contribute in painting the same stroke by stroke. It hopes to bring together researchers as well as practitioners from multiple dimensions of flexible systems thinking and would act as a platform for cross-fertilization of such diverse knowledge streams in an evolutionary manner. The efforts of various contributors may result into new business excellence and maturity models that would incorporate flexibility constructs explicitly along with other well known constructs of quality, and capability maturity. 